\title{
Computing Retinal Contour from Optical Biometry
}

\author{
Miguel Faria-Ribeiro*, Norberto López-Gil ${ }^{\dagger}$, Rafael Navarro ${ }^{\dagger}$, Daniela Lopes-Ferreira*, Jorge Jorge ${ }^{\ddagger}$, \\ and Jose Manuel González-Méijome
}

\begin{abstract}
Purpose. To describe a new methodology that derives horizontal posterior retinal contours from partial coherence interferometry $(\mathrm{PCl})$ and ray tracing using the corneal topography.

Methods. Corneal topography and $\mathrm{PCI}$ for seven horizontal visual field eccentricities correspondent to the central 60 degrees of the posterior pole were obtained in 55 myopic eyes. A semicustomized eye model based on the subject's corneal topography and the Navarro eye model was generated using Zemax-EE software. The model was used to compute the optical path length in the seven directions where PCI measurements were obtained. Vitreous chamber depth was computed using the $\mathrm{PCl}$ values obtained at each of those directions. Matlab software was developed to fit the best conic curve to the set of points previously obtained. We tested the limit in the accuracy of the methodology when the actual cornea of the subject is not used and for two different lens geometries.

Results. A standard eye model can induce an error in the retina sagitta estimation of the order of hundreds of micrometers in comparison with the semicustomized eye model. However, the use of a different lens model leads to an error of the order of tens of micrometers. The apical radius and conic constant of the average fit were $-11.91 \mathrm{~mm}$ and -0.15 , respectively. In general, a nasal-temporal asymmetry in the retina contour was found, showing mean larger values of vitreous chamber depth in the nasal side of the eye.
\end{abstract}

Conclusions. The use of a semicustomized eye model, together with optical path length measured by $\mathrm{PCl}$ for different angles, can be used to predict the retinal contour within tenths of micrometers. This methodology can be useful in studies trying to understand the effect of peripheral retinal location on myopia progression as well as modeling the optics of the human eye for a wide field.

(Optom Vis Sci 2014;91:00-00)

Key Words: partial coherence optical biometry, IOLMaster, retinal contour, myopia, model eye for a wide field

K nowledge of the posterior retinal contour is potentially useful to understand the mechanisms of emmetropization and myopia progression. ${ }^{1-3}$ Furthermore, the current knowledge in this field suggests that it might be possible to interfere with myopia progression by customizing the relative position of the peripheral image focusing regarding the retinal surface. ${ }^{4}$ To achieve a true customization of these treatments, it will be essential to know the actual position and shape of the retinal surface to design an optical device able to change the refraction in the desired way. ${ }^{5}$

*OD, MSc

${ }^{\dagger} \mathrm{PhD}$

*OD, $\mathrm{PhD}$

Clinical and Experimental Optometry Research Lab (CEORLab), Center of Physics, School of Sciences (Optometry), University of Minho, Braga, Portugal (MFR, DL-F, JJ, JG-M); and CiViUM, Facultad de Óptica y Optometría, Universidad de Murcia, Murcia (NL-G); and Instituto de Ciencia de Materiales de Aragón, Consejo Superior de Investigaciones Científicas-Universidad de Zaragoza, Zaragoza (RN), Spain.
Retinal contour can be determined by a number of techniques such as indirect inference from peripheral refraction, ${ }^{6,7} \mathrm{x}$-ray, ${ }^{8}$ magnetic resonance imaging, ${ }^{9-11}$ and, more recently, optical coherence tomography. ${ }^{12}$ Although magnetic resonance imaging is a very useful technique to evaluate the eyeball shape, it is not usually available in the context of a personalized optical prescription. It also lacks the resolution needed to achieve a detailed knowledge of the retinal contour at a micrometric level. On the other hand, optical coherence tomography is capable of producing highresolution images. However, to date, their limited field of analysis does not allow them to measure retinal curvature beyond the central 30 degrees, ${ }^{12}$ where some of the currently available optical treatments aim to have a significant optical effect. ${ }^{13-15}$

Mallen and Kashyap ${ }^{16}$ used partial coherence interferometry (PCI) to perform peripheral biometry using the IOLMaster, but their work has not dealt with the optical distortion in peripheral measures, when the IOLMaster infrared beam passes through the lens in an oblique direction. This was pointed out by Atchison and Charman ${ }^{17}$ 
as a potentially significant source of error. Previous work also fails to consider the different refractive indices of the eye's media, given that the IOLMaster measures the optical path length (OPL) between the corneal surface and the retina ${ }^{18}$ and uses a single average refractive index to derive the physical eye length (EL) from the OPL. ${ }^{19}$

Atchison and Charman ${ }^{17}$ have recently shown that PCI technology might be suitable to determine the retinal contour if the OPL within each component of the eye is known. They performed an interesting theoretical study using a Gullstrand eye model to identify potential errors when using PCI and demonstrated that an eye model together with ray tracing and experimental measurements of PCI could be used to find the position of the retina as a function of angle of the incident beam. Authors have also mentioned that an accurate description of the retinal contour depends on the eye model used. Partial coherence interferometry values for different angles are relatively easy to obtain using commercial instruments such as IOLMaster or the Lenstar. However, designing a realistic customized eye model can be very complex because of a lack of detailed measurements of the front and back surface of the lens and its gradient index. Conversely, there are a number of commercial systems available to obtain highly precise measurements of the corneal topography of the eye. Taking into account that we are measuring cornea-to-retina OPL and that the cornea sagittal heights at the points of intercept can vary significantly between subjects, we can presume that corneal topography will be an essential part of the eye model that should be used to obtain reliable data of the retinal contour from PCI measures. On the other hand, considering the relatively small changes in refractive indices within the eye, it might not be critical to know in detail the internal optics to compute the contour of the retina with an acceptable error margin.

In this context, the goal of this work was to study the possibilities of using a semicustomized eye model to derive the horizontal posterior retinal contour from measures of OPL obtained with PCI. The methodology described was used to estimate the retinal contour of a group of subjects.

\section{METHODS}

\section{Measurements and Subjects}

Eye length was measured in the nonpathological right eyes of 55 young (mean age, $22.04 \pm 1.75$ years) myopes with central refraction (mean sphere) ranging from -0.60 to -5.80 diopters (D) and axial length obtained with the IOLMaster (Carl Zeiss Meditec, Jena, Germany) ranging from 23.12 to $26.23 \mathrm{~mm}$. The clinical data used in this study were obtained from a previous study, ${ }^{20}$ where methodological details on data acquisition can be found. The study complied with the Declaration of Helsinki, and an institutional review board evaluated and approved the protocol. Pupil was dilated using tropicamide $1 \%$ (Tropicil; Laboratórios Edol, Portugal), which also permits to control accommodation. Pupil diameter was larger than $7 \mathrm{~mm}$ for all subjects, which guaranteed EL measurements up to 30 degrees. For each subject, three EL measures were averaged in seven horizontal eccentricities $(\boldsymbol{\theta})$ from 30 degrees nasal to 30 degrees temporal with respect to the visual axis in 10-degree steps. Negative and positive values of $\Theta$ represent nasal and temporal positions in the retinal plane, respectively. The procedure used was similar to the one previously described by Mallen and Kashyap, ${ }^{16}$ in which the patient rotates his eye without moving the head to fixate a printed Maltese cross through a beam splitter. At each measured eccentricity, the axis of the IOLMaster was readjusted to maintain an almost perpendicular alignment with the anterior corneal surface. This was controlled by the signal-to-noise ratio information provided by the instrument.

A narrow beam of coherent light coming from the IOLMaster, which enters the eye along the apparatus axis, is captured as a narrow beam coming out along the same axis after diffused reflection in the retina. Thus, following the Fermat principle,$^{21}$ the optical paths traveled by the ray going in and that coming out of the eye are the same.

Corneal topography was also measured using a commercial topographer (Medmont E-300, Vermont, Australia). For each subject, all measurements were performed in the right eye.

\section{Calculating Retinal Single Locations from IOLMaster Measurements}

Direct measurements of the EL by IOLMaster should not be used to obtain the position of the retina in the direction of measurement, as previously indicated. ${ }^{17}$ However, knowing that the IOLMaster uses an equivalent refractive index, $n_{\mathrm{eq}}=1.3549,{ }^{19}$ we can retrieve the OPL of the rays passing through the eye at a certain angle $(\theta)$ by multiplying EL by $n_{\mathrm{eq}}$. Then, assuming an homogeneous refractive index within the eye, measurements of EL made by the IOLMaster at each $\boldsymbol{\theta}$ direction can be related to the vitreous path length in the same direction using the following expression:

$$
\begin{aligned}
E L_{\text {IOLMASTER }}(\boldsymbol{\Theta}) * 1.3549 & =P L_{\text {CORNEA }}(\boldsymbol{\Theta}) * 1.3856 \\
& +P L_{\text {AQUEOUS }}(\boldsymbol{\Theta}) * 1.3459 \\
& +P L_{\text {LENS }}(\boldsymbol{\Theta}) * 1.4070 \\
& +P L_{\text {VITREOUS }}(\boldsymbol{\Theta}) * 1.3445
\end{aligned}
$$

where $1.3856,1.3459,1.4070$, and 1.3445 have been proposed to be the group refractive indices of cornea, aqueous, lens, and vitreous, respectively, for the wavelength used by the IOLMaster $(780 \mathrm{~nm}) .{ }^{19}$ Using a model eye and a ray tracing software Zemax-EE (Radiant Zemax Development, Redmond, WA), a ray was traced entering the eye perpendicular to the anterior cornea surface at each angle $\boldsymbol{\theta}$, that is, directed to the center of its sagittal radius of curvature (because of the asphericity nature of the cornea, this location will change for different angles $\theta$ ). From ray tracing, the direction and the physical distance traveled by the ray through the different media can be known within the eye model: $\operatorname{PL}_{\text {CORneA }}(\theta)$, $\operatorname{PL}_{\text {AQueOus }}(\theta)$, and $\operatorname{PL}_{\text {LENS }}(\theta)$. Those distances can be used in equation 1 to calculate the physical length of the vitreous chamber, PLVITREous $(\theta)$, and obtain the seven points corresponding to the $(x, z)$ coordinates of the ray intercept at the retina, for each value of $\Theta$ referenced to a plane normal to the visual axis that crosses the fovea at point $(0,0)$.

\section{Semicustomized Eye Model}

For each subject, a semicustomized eye model was built based on the Navarro eye model ${ }^{22}$ (Table 1), with the front corneal surface replaced with a Zernike Standard Sag surface ${ }^{23}$ computed from the topographic data of the subject. ${ }^{24,25}$ This surface includes a regular revolution conic surface plus a Zernike polynomial expansion, which accounts for departures of the real surface from the regular basis. Individual data obtained from anterior elevation 
TABLE 1.

Unaccommodated Navarro eye model parameters

\begin{tabular}{|c|c|c|c|c|c|}
\hline \multicolumn{2}{|c|}{ Surface: type } & \multirow{2}{*}{$\begin{array}{c}\text { Comment } \\
\text { Cornea } \\
\text { (anterior) }\end{array}$} & \multirow{2}{*}{$\frac{\text { Radius, } \mathrm{mm}}{7.72}$} & \multirow{2}{*}{$\frac{\text { Thickness, } \mathrm{mm}}{0.55000}$} & \multirow{2}{*}{$\frac{\text { Conic }}{-0.2600}$} \\
\hline 1 & Standard & & & & \\
\hline 2 & Standard & $\begin{array}{l}\text { Cornea } \\
\quad \text { (posterior) }\end{array}$ & 6.50 & 3.05000 & 0.0000 \\
\hline STO & Standard & Pupil & & & \\
\hline 4 & Standard & $\begin{array}{l}\text { Lens } \\
\quad \text { (anterior) }\end{array}$ & 10.20 & 4.00000 & -3.1316 \\
\hline 5 & Standard & $\begin{array}{l}\text { Lens } \\
\quad \text { (posterior) }\end{array}$ & -6.00 & 16.40398 & -1.0000 \\
\hline IMA & Standard & Retina & -12.00 & & 0.0000 \\
\hline
\end{tabular}

STO indicates stop; IMA, image.

topography were fitted to the Zernike standard surface equation by a least-squares method implemented in Matlab (The MathWorks, Natick, MA). ${ }^{26}$ The phase refractive indices of the Navarro eye were changed to match the ones proposed by Hitzenberger ${ }^{19}$ for an envelope of infrared waves as mentioned in equation 1.

Zemax-EE was then used to compute the ray tracing for each angle $\theta$. In all cases, especially for large negative or positive values of $\Theta$, the beam from the instrument does not travel in a straight line inside the eye. Thus, the point where the ray intercepts with the retina does not lie in the direction of measurement as previously considered.

\section{Estimating Retinal Contour}

Traditionally, ocular surfaces are described in terms of conic sections. A software was developed in Matlab (The MathWorks) based on a least-squares method to compute the best fit of a conic surface to the seven retinal location points obtained using the methodology described above. The software was programmed to allow a free orientation of the fitted conic sections to express possible asymmetry aspects from the retina contour that would be lost if the conic sections were fitted in their canonical form. The general equation of the conic is a second-order polynomial of two variables $x, z$ :

$$
a_{20} x^{2}+a_{02} z^{2}+a_{11} x z+a_{10} x+a_{01} z+a_{0}=0
$$

There are five independent parameters plus an arbitrary scale factor. The fitting provided the values of the coefficients $a_{\mathrm{ij}}$. From these coefficients, we computed the apex radii $(R)$, applying standard methods of linear algebra. The first step is finding the affine transform (rotation and translation) that brings the conic to its canonic position that is centered and aligned with the coordinate system. Details are given in another work ${ }^{24}$ for the general three-dimensional case. After finding the orientation $(\beta)$ and apex coordinates $\left(x_{0}, y_{0}\right)$ of the conic, we can pass to the canonic expression:

$$
\frac{x^{2}}{a^{2}}+\frac{z^{2}}{c^{2}}=1
$$

where $a$ and $c$ are the semiaxes. The apex radius and the conic constant can now be calculated using the following equations:

$$
\begin{gathered}
R=a^{2} / \mathrm{c} \\
Q=\mathrm{a}^{2} / \mathrm{c}^{2}-1
\end{gathered}
$$

Once the software was applied to all the subjects, we computed the mean and the SD of the fitting errors to the conic curves (RMS). The RMS fit errors higher than the mean \pm 3 SDs were considered poor fits and were excluded. This represents a confidence interval of nearly $100 \%$ (99.6\%) because, at this stage, the goal was to discard only those cases that do not follow the conic model with good accuracy. Seven cases of an initial number of 62 were discarded because of poor fit results according to this criterion. For simplicity, all the results were normalized using the conic equations for a maximum horizontal distance from the fovea $(x)$ of $\pm 8 \mathrm{~mm}$ (average value of $x$ for \pm 30 degrees of incidence angle) and plotted in 2-mm steps.

\section{Testing the Validity of the Semicustomized Eye Model}

Finally, the validity of using a semicustomized modeling approach was tested by performing the calculations in two different ways. First, the retinal contour was computed using the anterior cornea from the Navarro eye model, consisting of a rotationally symmetric aspheric surface with an apical radius of $7.72 \mathrm{~mm}$ and a conic constant of $-0.26 .{ }^{22} \mathrm{Next}$, the retinal contour was computed by incorporating the actual corneal topography from the subject (semicustomized approach). Results were compared to evaluate the importance of using corneal topography in our methodology.

In the second test, the need for a highly customized eye model was evaluated by including different values of lens thickness and curvature. In addition to all the intersubject variability, the thickness and shape of the crystalline lens change with age, becoming larger and thicker. ${ }^{20,27}$ The use of an age-independent lens with a constant shape and thickness in our semicustomized model could then result in a relevant source of error in determining the retinal contour. This potential source of error was checked by computing the retinal contour using a full Navarro eye model and then changing its lens to match the geometries of a 20 - and a 70 -year-old lens. This was done by modifying the values of both the apical radius of the front surface and the axial lens thickness of the lens, according to the experimental data of Atchison and coworkers. ${ }^{20}$ In the procedure, the full Navarro eye model with a spherical retina of $-12 \mathrm{~mm}^{28}$ radius was used to obtain the readings that the IOLMaster would produce for the seven angle $\theta$ values analyzed. Those values were then used to recompute the retinal contour using the two lens geometries mentioned above.

\section{Statistical Analysis}

Average values of the sagittal height of the retina from the plane of reference were derived. The dispersion of data was represented by error bars representing $2 \pm$ SD to account for $95 \%$ of the population sampled and detect possible outliers. Normality of data under analysis was verified by the Kolmogorov-Smirnov test. Differences between sagittal heights at each eccentric measure were computed by paired-sample $t$ test. The level of significance was set for $\mathrm{p}<0.05$.

\section{RESULTS}

Fig. 1 presents the mean retinal contour obtained in the 55 right eyes using the semicustomized eye model. The large value of the error bars at $\pm 8 \mathrm{~mm}$ from the fovea (corresponding to approximate $\theta= \pm 30$ degrees) indicates the large variability in shape between subjects. It can also be noted that there is a 


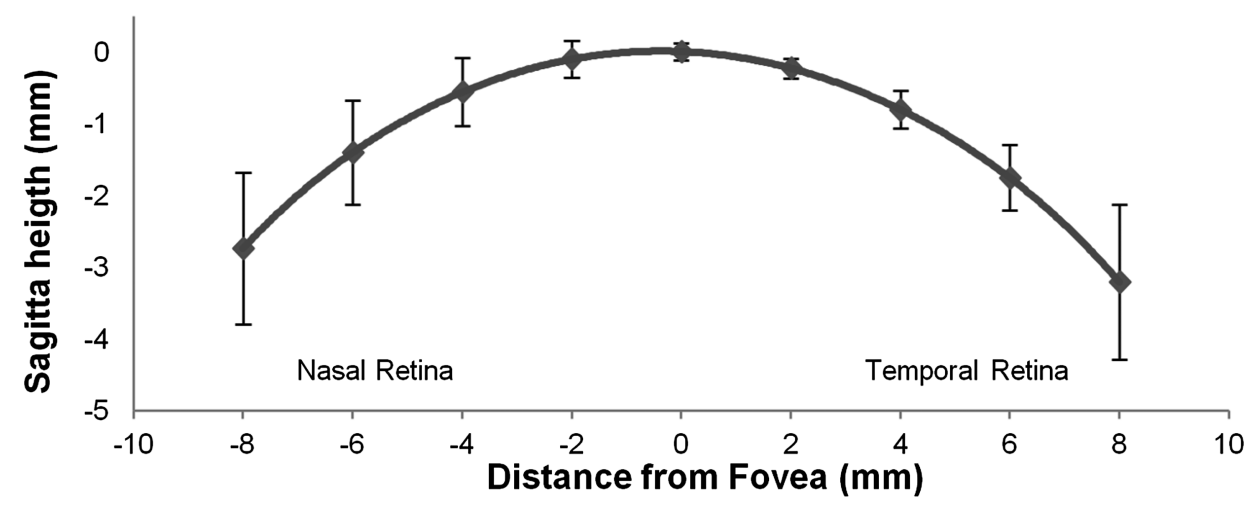

\section{FIGURE 1.}

Average sagitta values of the 55 subjects fitted with a conic $(R=-11.91 \mathrm{~mm}, Q=-0.15)$. Error bars represent \pm 2 SDs.

difference in the mean shape between the nasal and temporal hemifields. A paired $t$ test comparing the individual sagitta values obtained for opposite retina hemifield locations at 2-, 4-, 6 -, and 8 -mm horizontal coordinate confirmed the asymmetry $\left(t_{54}=\right.$ $5.74,6.17,7.24,7.61 ; \mathrm{p}<0.001)$. Axial length correlated with central mean sphere only at a moderate level $\left(R^{2}=0.2 ; \mathrm{p}<0.001\right)$. Retina sagitta height at central and peripheral locations as well as asymmetry between nasal and temporal hemifields were not correlated to a significant level with axial length or central spherical equivalent refractive error.

For comparison purposes with previous data in the literature, ${ }^{29,30}$ the mean retinal contour was also plotted as a function of the angle of the incident beam $(\Theta)$ (Fig. 2). Two particular cases were included corresponding to those eyes that showed the largest positive or negative difference between the retina sagitta heights at opposite hemifield locations (nasal-temporal asymmetry).

Table 2 shows the statistics of the fitted 55 conics as well as the parameters of the conic fit to the average data points.

Fig. 3 plots the average differences for the retina sagitta heights $(\Delta \mathrm{Sag})$ across the central $16 \mathrm{~mm}$ of the horizontal posterior pole obtained when using the generic cornea of the Navarro eye instead of individual corneal topographic data. Negative or positive $\Delta S$ ag values were obtained whenever the generic eye model predicted steeper or flatter retinal contours, respectively, than the ones obtained with the semicustomized eye model.

Fig. 4 shows the differences in the retina sagitta height when two different lens geometries were used for the computation. For this purpose, the lens of the Navarro eye was changed to match the thickness and curvatures of a 20 - and a 70-year-old eye according to the parameters reported by Atchison el al. ${ }^{20}$ Negative $\Delta$ Sag values represent a steeper retina when using a different lens thickness and anterior surface radius compared with the one obtained with the generic Navarro eye lens geometry.

\section{DISCUSSION}

The present work describes a new method to derive a twodimensional retinal contour within the central $16 \mathrm{~mm}$ of the horizontal posterior pole using a clinically available technology to measure intraocular dimensions, corneal topography, and numerical ray tracing.

As IOLMaster measures the OPL between the cornea and the retina, it can be expected that differences in the anterior elevation of the cornea (initial point of the OPL) as well as the length of the vitreous chamber (locating the final point of the OPL) and thickness of the crystalline lens should be critical for the computation of the retina shape using PCI measures. Our results in 55 eyes agree with this rationale, showing that the difference between using an eye model with a generic cornea and one with a customized cornea can lead to an error in the calculation of the retinal position up to $244 \mu \mathrm{m}$ (Fig. 3), which represents an error in the refraction of about $0.75 \mathrm{D}$ (roughly, $1 \mathrm{~mm}$ of increase in axial length corresponds to $-3.0 \mathrm{D}$ ). Although not tested, we can assume that, in eyes with pathological corneas, such as keratoconus or corneal penetrating keratoplastia, where deviations from a regular shape are much larger than in the

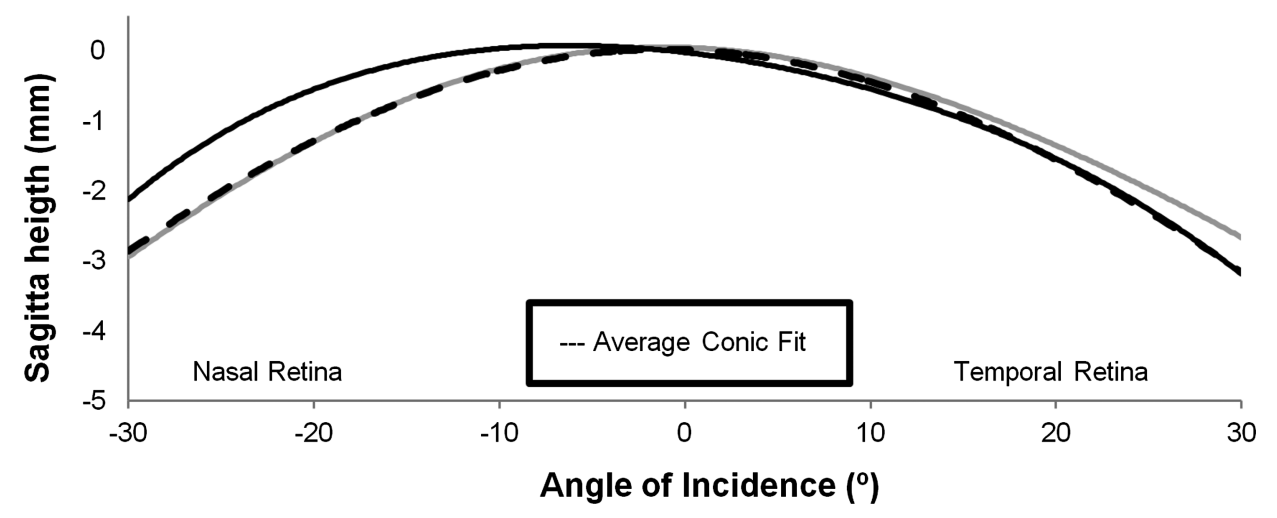

FIGURE 2.

Average conic fit as a function of angle in object space (dotted line) and example of Nasal-Temporal retinal asymmetry of two individuals (black and gray lines). 
TABLE 2.

Descriptive statistics of the parameters of the conic and of the RMS fit error

\begin{tabular}{|c|c|c|c|c|c|c|}
\hline & & ange & & Average & SD & Fit to average data \\
\hline $\mathrm{RMS}, \mathrm{mm}$ & 0.01 & to & 0.10 & 0.04 & 0.03 & 0.0023 \\
\hline Apex radius, mm & -19.06 & to & -7.26 & -11.78 & 2.67 & -11.91 \\
\hline Conic constant & -2.37 & to & 3.38 & -0.29 & 1.24 & -0.15 \\
\hline Orientation, $\beta$, degrees & -43.47 & to & 44.51 & 0.09 & 16.68 & 11.56 \\
\hline Apex $x_{0}, \mathrm{~mm}$ & -1.91 & to & 1.72 & -0.34 & 0.60 & -0.36 \\
\hline Apex $z_{0}, \mathrm{~mm}$ & -0.28 & to & 0.21 & 0.03 & 0.09 & 0.018 \\
\hline
\end{tabular}

The shape of the conic is determined by the curvature radius at the apex and the conic constant; the orientation, $\beta$, is the angle between the major axis of the conic and the visual axis, and the position is determined by the apex coordinates $x_{0}, z_{0}$.

*Kolmogorov-Smirnov: Lilliefors significance correction; $p<0.001$ for all cases.

population evaluated, the retinal contour estimates will be much more affected.

In our experiment, accommodation was artificially relaxed using tropicamide so the lens curvatures should not change during the measurements. We did not have direct measurements of the lens curvatures of our subjects so we were not able to fully customize the eye models. Nevertheless, assuming that the cornea and lens changes in thickness with respect to that presented in the Navarro eye model are usually less than 150 and $500 \mu \mathrm{m}$, respectively, and taking into account that the changes in refractive index between those two refractive elements and the humors are about 0.04 and 0.06 for the cornea-aqueous humor and lens-aqueous or vitreous humor (equation 1), we can expect that changes in OPL with the lens will differ about $36 \mu \mathrm{m}$ between different eyes, except for phakic or pseudophakic eyes. Moreover, our previous simulation work has also shown that the estimation of the actual axial length of the eye with PCI might be biased only by $56 \mu \mathrm{m}$ in eyes with different lens thicknesses within a range of axial lengths from 20 to $30 \mathrm{~mm} .{ }^{31}$ The simulations presented in this work have also confirmed this finding that the incorporation of specific lens parameters into the model won't produce a significant different in the estimation of the actual retinal position. Yet we implemented a partial customization of the lens by considering age-related changes of lens curvatures and thicknesses. Fig. 4 shows that the difference in the retinal contour for the two lens configurations used in the simulations are within the range of tens of microns. This value is typically in the order of magnitude of the error of the axial length measures given by the
IOLMaster ${ }^{32}$ and represents a change in the equivalent refractive sphere of the order of $0.1 \mathrm{D}$, which also are in the order of the repeatability of the open-field autorefractometers usually used in peripheral refractive measurements. ${ }^{33}$ In addition to the small difference in the OPL for different optics inside the eye, there is also a change in the direction of the ray exiting the lens. This will also modify the retinal contour estimate by causing a small transverse deviation at the retinal plane. Although the actual deviation will depend on the particular model eye used, the results in Fig. 4 suggest that the errors induced by this fact should be small for horizontal locations up to $\pm 8 \mathrm{~mm}$ away from the fovea, which represent approximately 60 degrees of visual field.

This study highlights the intersubject differences in the contour of the posterior pole of the low to moderate myopic ${ }^{34}$ eye using a method that combines actual PCI measures with correction mechanisms based on ray tracing (Figs. 1, 2). These differences can reach $2.3 \mathrm{~mm}$ in sagitta height at $8 \mathrm{~mm}$ horizontal coordinate. The majority of the subjects ( 48 of 55) presented a positive asymmetry (Nasal Sag-Temporal Sag), that is, longest vitreous chamber in the nasal hemifield (Fig. 1), which is in agreement with other reported results. $2,29,35$

Although previous studies have also shown that the posterior shape of the eye might be related to the level of axial elongation, such that longer eyes will tend to be steeper in the posterior pole, ${ }^{10,36,37}$ in this study, we have not found significant correlations between retinal shape and axial length or even central refraction. This is not surprising considering that $67 \%$ of the eyes included in our sample were

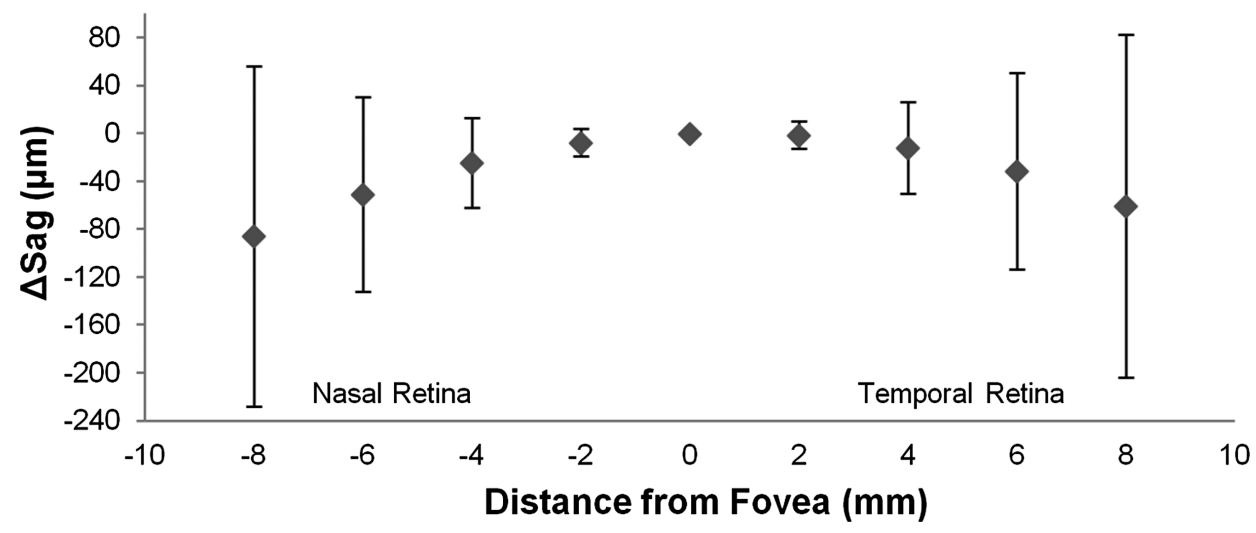

FIGURE 3.

Effect of the customization of the cornea. Differences in the average retinal contour sagittas obtained when applying a generic cornea in the eye model. Average differences rapidly increase with eccentricity, which suggests the need for a semicustomized eye model. Nonzero average differences indicate that both models predict different contours. Error bars represent \pm 2 SDs. 


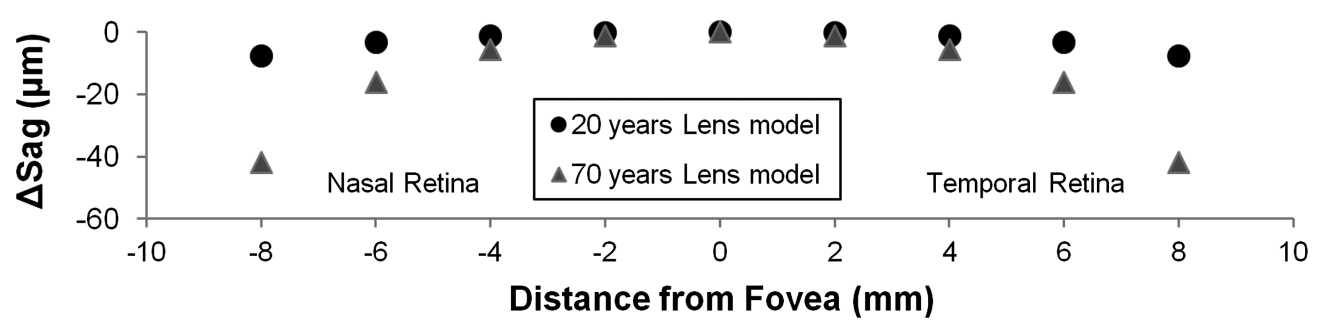

\section{FIGURE 4.}

Effect of the customization of the lens. Differences in the retinal contour sagittas of the Navarro eye obtained when using a 20- and a 70-year-old lens model instead of the generic lens geometry. Differences remain small even for large eccentricities, which suggest that there is no need for a full custom eye model. Nonzero differences indicate that the two age-dependent models predict different contours.

low myopes (up to $-3.00 \mathrm{D}$ of mean sphere) and may not have yet suffered enough stretching or elongation forces that would be reflected in the contour of the posterior pole. Rather, our sample might be a good example of how random the posterior ocular shape might be in low to moderate myopes - most habitually targeted by myopia retention treatments. ${ }^{38-40}$

Assuming that peripheral imagery has an influence on emmetropization and in the development of refractive errors, differences as large as $2 \mathrm{~mm}$ in the estimation of the retinal location at an angle of 30 degrees and beyond might help explain why eyes with similar refractive errors react differently to the same treatment. ${ }^{38-42}$ The results from the present study stress the need for semicustomized eye models incorporating actual corneal topography and actual retinal contour when it comes to designing optical treatments for wide angles. ${ }^{43}$

In a future approach, other meridians can be assessed using the same methodology to obtain a three-dimensional retinal surface. In that case, more complex surfaces than conics will be probably needed.

\section{ACKNOWLEDGMENTS}

This study has been funded by FEDER through the COMPTETE Program and by the Portuguese Foundation for Science and Technology (FCT) in the framework of projects PTDC/SAU-BEB/098391/2008, PTDC/SAUBEB/098392/2008, and the Strategic Project PEST-C/FIS/UI607/2011. N.L. was also supported by a Fundación Séneca de la Región de Murcia grant 15312/PI/10. R.N. was supported by the Spanish Ministry of Economia y Competitividad and European Union grant FIS2011-22496 and by the Government of Aragón group E99. We thank Larry N. Thibos for his comments on the manuscript.

The authors have no proprietary interest in any of the devices mentioned in this article.

Received August 9, 2013; accepted February 6, 2014.

\section{REFERENCES}

1. Dunne MC. A computing scheme for determination of retinal contour from peripheral refraction, keratometry, and A-scan ultrasonography. Ophthalmic Physiol Opt 1995;15:133-43.

2. Logan NS, Gilmartin B, Wildsoet CF, Dunne MC. Posterior retinal contour in adult human anisomyopia. Invest Ophthalmol Vis Sci 2004; 45:2152-62.

3. Atchison DA, Pritchard N, Schmid KL, Scott DH, Jones CE, Pope JM. Shape of the retinal surface in emmetropia and myopia. Invest Ophthalmol Vis Sci 2005;46:2698-707.

4. Smith EL, 3rd. Optical treatment strategies to slow myopia progression: effects of the visual extent of the optical treatment zone. Exp Eye Res 2013;114:77-88.
5. Flitcroft DI. The complex interactions of retinal, optical and environmental factors in myopia aetiology. Prog Retin Eye Res 2012; 31:622-60.

6. Logan NS, Gilmartin B, Dunne MC. Computation of retinal contour in anisomyopia. Ophthalmic Physiol Opt 1995;15:363-6.

7. Tabernero J, Schaeffel F. More irregular eye shape in low myopia than in emmetropia. Invest Ophthalmol Vis Sci 2009;50:4516-22.

8. Deller JF, O'Connor AD, Sorsby A. X-ray measurement of the diameters of the living eye. Proc R Soc Med 1947;134:456-67.

9. Singh KD, Logan NS, Gilmartin B. Three-dimensional modeling of the human eye based on magnetic resonance imaging. Invest Ophthalmol Vis Sci 2006;47:2272-9.

10. Atchison DA, Jones CE, Schmid KL, Pritchard N, Pope JM, Strugnell WE, Riley RA. Eye shape in emmetropia and myopia. Invest Ophthalmol Vis Sci 2004;45:3380-6.

11. Moriyama M, Ohno-Matsui K, Hayashi K, Shimada N, Yoshida T, Tokoro T, Morita I. Topographic analyses of shape of eyes with pathologic myopia by high-resolution three-dimensional magnetic resonance imaging. Ophthalmology 2011;118:1626-37.

12. Clark C, Konynenbelt B, Elsner AE, Toco Chui YP, VanNasdale DA. Retinal changes and peripheral refraction using optical coherence tomography. Optom Vis Sci 2012;89:E-Abstract 120623.

13. Rosen R, Jaeken B, Lindskoog Petterson A, Artal P, Unsbo P, Lundstrom L. Evaluating the peripheral optical effect of multifocal contact lenses. Ophthalmic Physiol Opt 2012;32:527-34.

14. Lopes-Ferreira D, Ribeiro C, Maia R, Garcia-Porta N, Queiros A, Villa-Collar C, Gonzalez-Meijome JM. Peripheral myopization using a dominant design multifocal contact lens. J Optom 2011; 4:14-21.

15. Queiros A, Gonzalez-Meijome JM, Jorge J, Villa-Collar C, Gutierrez AR. Peripheral refraction in myopic patients after orthokeratology. Optom Vis Sci 2010;87:323-9.

16. Mallen EA, Kashyap P. Technical note: measurement of retinal contour and supine axial length using the Zeiss IOLMaster. Ophthalmic Physiol Opt 2007;27:404-11.

17. Atchison DA, Charman WN. Can partial coherence interferometry be used to determine retinal shape? Optom Vis Sci 2011;88:601-7.

18. Haigis W. Optical coherence biometry. Dev Ophthalmol 2002;34: 119-30.

19. Hitzenberger CK. Optical measurement of the axial eye length by laser Doppler interferometry. Invest Ophthalmol Vis Sci 1991;32: 616-24.

20. Atchison DA, Markwell EL, Kasthurirangan S, Pope JM, Smith G, Swann PG. Age-related changes in optical and biometric characteristics of emmetropic eyes. J Vis 2008;8:29 1-0.

21. Born M, Wolf E. Principles of Optics, 6th ed. Oxford, UK: Pergamon; 1980. 
22. Navarro R, Santamaría J, Bescós J. Accommodation-dependent model of the human eye with aspherics. J Opt Soc Am (A) 1985;2: 1273-81.

23. ZEMAX Optical Design Program User's Guide. ZEMAX Development Corporation; 2005:285-6.

24. Navarro R, Gonzalez L, Hernandez-Matamoros JL. On the prediction of optical aberrations by personalized eye models. Optom Vis Sci 2006;83:371-81.

25. Navarro R. The optical design of the human eye: a critical review. J Optom 2009;2:3-18.

26. Navarro R, González L, Hernandez JL. Optics of the average normal cornea from general and canonical representations of its surface topography. J Opt Soc Am (A) 2006;23:219-32.

27. Dubbelman $M$, van der Heijde GL. The shape of the aging human lens: curvature, equivalent refractive index and the lens paradox. Vision Res 2001;41:1867-77.

28. Escudero-Sanz I, Navarro R. Off-axis aberrations of a wide-angle schematic eye model. J Opt Soc Am (A) 1999;16:1881-91.

29. Ehsaei A, Chisholm CM, Pacey IE, Mallen EA. Off-axis partial coherence interferometry in myopes and emmetropes. Ophthalmic Physiol Opt 2013;33:26-34.

30. Schmid GF. Association between retinal steepness and central myopic shift in children. Optom Vis Sci 2011;88:684-90.

31. Faria-Ribeiro M, Lopes-Ferreira D, Lopez-Gil N, González-Méijome JM. Errors associated with IOLMaster biometry as a function of internal ocular dimensions. J Optom 2014;7:75-78.

32. Santodomingo-Rubido J, Mallen EA, Gilmartin B, Wolffsohn JS. A new non-contact optical device for ocular biometry. Br J Ophthalmol 2002;86:458-62.

33. Davies LN, Mallen EA, Wolffsohn JS, Gilmartin B. Clinical evaluation of the Shin-Nippon NVision-K 5001/Grand Seiko WR5100K autorefractor. Optom Vis Sci 2003;80:320-4.

34. Maduka Okafor FC, Okoye OI, Eze BI. Myopia: a review of literature. Niger J Med 2009;18:134-8.

35. Faria-Ribeiro M, Queiros A, Lopes-Ferreira D, Jorge J, GonzalezMeijome JM. Peripheral refraction and retinal contour in stable and progressive myopia. Optom Vis Sci 2013;90:9-15.
Retinal Contour from Optical Biometry-Faria-Ribeiro et al. 7

36. Mutti DO, Sholtz RI, Friedman NE, Zadnik K. Peripheral refraction and ocular shape in children. Invest Ophthalmol Vis Sci 2000;41: 1022-30.

37. Stone RA, Flitcroft DI. Ocular shape and myopia. Ann Acad Med Singapore 2004;33:7-15.

38. Anstice NS, Phillips JR. Effect of dual-focus soft contact lens wear on axial myopia progression in children. Ophthalmology 2011;118: 1152-61.

39. Cho P, Cheung SW. Retardation of myopia in Orthokeratology (ROMIO) study: a 2-year randomized clinical trial. Invest Ophthalmol Vis Sci 2012;53:7077-85.

40. Sankaridurg P, Holden B, Smith E, 3rd, Naduvilath T, Chen X, de la Jara PL, Martinez A, Kwan J, Ho A, Frick K, Ge J. Decrease in rate of myopia progression with a contact lens designed to reduce relative peripheral hyperopia: one-year results. Invest Ophthalmol Vis Sci 2011;52:9362-7.

41. Kang P, Swarbrick H. Peripheral refraction in myopic children wearing orthokeratology and gas-permeable lenses. Optom Vis Sci 2011;88:476-82.

42. Sankaridurg P, Donovan L, Varnas S, Ho A, Chen X, Martinez A, Fisher S, Lin Z, Smith EL, 3rd, Ge J, Holden B. Spectacle lenses designed to reduce progression of myopia: 12-month results. Optom Vis Sci 2010;87:631-41.

43. Wei $X$, Thibos L. Designing contact lenses for a wide field of view via ocular wavefront tomography. J Optom 2010;3:125-33.

Miguel Faria-Ribeiro

Clinical and Experimental Optometry Research Lab (CEORLab) Center of Physics (Optometry)

University of Minho 4710-057 Braga Portugal e-mail:mig.afr@gmail.com 